\begin{tabular}{|c|l|}
\hline Title & Efficient growth of anodic films on magnesium in organic electrolytes containing fluoride and water \\
\hline Author(s) & $\begin{array}{l}\text { Habazaki, Hiroki; Kataoka, Fumitaka; Tsuji, Etsushi; A oki, Y oshitaka; Nagata, Shinji; Skeldon, Peter; Thompson, } \\
\text { George E. }\end{array}$ \\
\hline Citation & $\begin{array}{l}\text { Electrochemistry Communications, 46,30-32 } \\
\text { https://doi.org/10.1016/.elecom.2014.06.011 }\end{array}$ \\
\hline Issue Date & 201409 \\
\hline Doc URL & http://hdl.handle.net/2115/57662 \\
\hline Type & article (author version) \\
\hline File Information & HIROKIElecom_V er2-ps2.pdf \\
\hline
\end{tabular}

Instructions for use 


\section{Efficient Growth of Anodic Films on Magnesium in Organic Electrolytes Containing Fluoride and Water}

Hiroki Habazaki ${ }^{1,2, *}$, Fumitaka Kataoka ${ }^{2}$, Etsushi Tsuji ${ }^{1,2}$, Yoshitaka Aoki ${ }^{1,2}$, Shinji Nagata ${ }^{3}$, Peter Skeldon ${ }^{4}$ and George E. Thompson ${ }^{4}$

${ }^{1}$ Division of Materials Chemistry \& Frontier Chemistry Center, Faculty of Engineering, Hokkaido University, Sapporo, Hokkaido 060-8628, Japan

${ }^{2}$ Graduate School of Chemical Sciences and Engineering, Hokkaido University, Sapporo, Hokkaido 060-8628, Japan

${ }^{3}$ Institute for Materials Research, Tohoku University, Sendai 980-8577, Japan

${ }^{4}$ Corrosion and Protection Centre, School of Materials, The University of Manchester, M13 9PL, UK

*Corresponding author; E-mail: habazaki@eng.hokudai.ac.jp; TEL \& FAX: +81-11-706-6575 


\section{Abstract}

The present study reports, for the first time, the highly efficient formation of barrier-type anodic films, with flat and parallel metal/film and film/electrolyte interfaces, on magnesium in ethylene glycol electrolytes containing ammonium fluoride and water. The anodizing voltage increases linearly with time during galvanostatic anodizing at $10 \mathrm{~A} \mathrm{~m}^{-2}$ up to $350 \mathrm{~V}$. The anodic film formed to $200 \mathrm{~V}$ is $247 \mathrm{~nm}$ thick, containing a crystalline $\mathrm{MgF}_{2}$ phase. Analysis by Rutherford backscattering spectroscopy discloses the film composition of $\mathrm{MgF}_{1.8} \mathrm{O}_{0.1}$ and Pilling-Bedworth ratio (PBR) of 1.67. The PBR value greater than unity and the formation of chemically stable fluoride-based films may contribute to the film growth at high current efficiency.

Keywords; anodizing, magnesium, anodic film, organic electrolyte, fluoride

\section{Introduction}

Anodizing of magnesium and its alloys is an important surface treatment process to improve corrosion resistance, paint adhesion and wear resistance. The anodic films formed on magnesium usually have a porous structure, with a thin barrier layer sandwiched between the porous layer and metal substrate. Unlike other valve metals, including aluminum, titanium, zirconium, niobium, tantalum and tungsten, there are no reports on the formation of barrier-type anodic films on magnesium at high current efficiency. Thus, fundamental understanding of the ionic transport process during anodizing of magnesium is still limited, although many studies have been carried out on the formation of anodic films on magnesium and its alloys $[1,2]$.

Recently, fluoride-containing organic electrolytes have been utilized to form self-organized nanotubular and nanoporous anodic films on titanium [3, 4], zirconium $[5,6]$, niobium [7], tantalum [8] iron [9-11] and stainless steel [12]. The use of organic electrolytes enables the formation of thick porous anodic films on iron and stainless steel, and improves the uniformity of the self-ordered pore or nanotubular array as well as the thickening of the anodic films.

A few studies have been conducted on anodizing of magnesium in organic electrolytes. Brunner et al. reported the formation of black porous anodic layers in water-free methanol or ethanol electrolytes [13]. The formation of barrier layers was reported by Asoh and Ono [14]. They used trimetylamine-containing ethylene glycol electrolytes with $10-40 \%$ water. The concentration of water influenced largely the growth behavior of the anodic films. Turhan et al. formed self-ordered magnesium oxy-fluoride nanoporous/tubular layers on WE43 magnesium alloy in HF-containing ethylene glycol electrolyte [15].

In the present study, we used ethylene glycol electrolyte containing $\mathrm{NH}_{4} \mathrm{~F}$ and a small amount of water. In contrast to the HF-containing ethylene glycol electrolyte, the anodic films 
formed in the present electrolyte were barrier-type with a growth efficiency close to $100 \%$. The structure and composition of the resultant films were characterized by transmission electron microscopy (TEM), scanning electron microscopy (SEM), X-ray diffraction (XRD) and Rutherford backscattering spectroscopy (RBS). The reason for the efficient film growth in the present anodizing condition is discussed.

\section{Experimental}

Thin magnesium films of $\sim 260 \mathrm{~nm}$ thickness were magnetron-sputtered onto glass or flat, anodized aluminum substrates using a 99.9\% magnesium target. The magnetron-sputtered specimens were used to avoid the influence of the second phases in bulk magnesium and its alloys on the anodic film growth. The deposited specimens were anodized at a constant current density of $10 \mathrm{~A} \mathrm{~m}^{-2}$ in ethylene glycol electrolyte containing $0.1 \mathrm{~mol} \mathrm{dm}^{-3}$ $\mathrm{NH}_{4} \mathrm{~F}$ and $0.1 \mathrm{~mol} \mathrm{dm}^{-3} \mathrm{H}_{2} \mathrm{O}$ at $293 \mathrm{~K}$ to selected voltages. A two-electrode cell with a platinum counter electrode was used. After anodizing, the specimens were washed in milli-Q water and dried in the ambient atmosphere. For comparison, anodizing was also carried out in an aqueous electrolyte containing $0.1 \mathrm{~mol} \mathrm{dm}^{-3} \mathrm{NH}_{4} \mathrm{~F}$.

Phases in the anodized specimens were identified by a Rigaku, RINT-2000 X-ray diffractometer using $\mathrm{Cu} K \alpha$ radiation $(\lambda=0.15418 \mathrm{~nm})$ under an $\alpha-2 \theta$ mode $\left(\alpha=1^{\circ}\right)$. Cross-sections of the anodized specimens were observed by a JEOL, JEM-2000FX transmission electron microscope operated at $200 \mathrm{kV}$. Electron transparent sections were prepared employing a Hitachi FB2100 Focused Ion Beam system. The surfaces of the anodized specimens were observed using a JEOL JSM-6500F field emission scanning electron microscope. Compositions of the alloy and anodic films were investigated by RBS, using 2.0 $\mathrm{MeV} \mathrm{He}^{2+}$ ions supplied by a tandem-type accelerator at Institute for Materials Research, Tohoku University, with detection of scattered ions at $170^{\circ}$. Data were analyzed using the RUMP program [16].

\section{Results and Discussion}

Anodizing of magnetron-sputtered magnesium at a constant current density of $10 \mathrm{~A}$ $\mathrm{m}^{-2}$ in the ethylene glycol (EG) electrolyte resulted in a linear voltage rise at a rate of $1.0 \mathrm{~V} \mathrm{~s}^{-1}$ up to $350 \mathrm{~V}$ at which the deposited magnesium film was almost completely anodized. In the aqueous electrolyte containing $\mathrm{NH}_{4} \mathrm{~F}$, however, the voltage rise was slow $\left(\sim 0.4 \mathrm{~V} \mathrm{~s}^{-1}\right)$ and terminated at $50 \mathrm{~V}$ because of film breakdown. Thus, the use of the organic electrolyte appears to be beneficial for uniform film growth. Figures $1 \mathrm{a}$ and $1 \mathrm{~b}$ show scanning electron micrographs of the specimen surfaces before and after anodizing to $200 \mathrm{~V}$ respectively. The as-deposited specimen reveals hexagonal grains, reflecting the hcp phase of magnesium metal. The observation of the hexagonal-shaped grains suggests that the deposited magnesium film may have an (0001) preferred orientation. After anodizing to $200 \mathrm{~V}$ in the organic electrolyte, 
the surface becomes smoother and no characteristic feature is seen in the scanning electron micrograph. In contrast, an anodic film with a rough surface is developed in the aqueous electrolyte (Fig. 1c). The XRD pattern of the anodic film formed to $350 \mathrm{~V}$ in the organic electrolyte (Fig. 2) discloses the presence of the $\mathrm{MgF}_{2}$ phase, although the respective diffraction lines are weak and have relatively wide peak widths. A halo pattern found between $20-30^{\circ}$ in Fig. 2 is associated mainly with the glass substrate.

The formation of a barrier-type anodic film is obvious from the transmission electron micrograph of Fig. 3a. The anodic film formed to $200 \mathrm{~V}$ is $247 \mathrm{~nm}$ thick and has sharp, flat and parallel metal/film and film/electrolyte interfaces. The formation ratio of $1.24 \mathrm{~nm} \mathrm{~V}^{-1}$ is similar to that for the anodic films formed on aluminum in neutral aqueous electrolytes [17]. A selected area diffraction pattern obtained from the anodic film (Fig. 3b) reveals the presence of the $\mathrm{MgF}_{2}$ phase, which is consistent with the XRD pattern. A $\sim 30 \mathrm{~nm}$-thick band with a light contrast appears at the $60 \%$ of the film thickness from the film/electrolyte interface. EDS analysis revealed that the light region had a slightly high $\mathrm{O} / \mathrm{F}$ ratio compared with the other film regions, suggesting that the band may be associated with an air-formed film, which was present before anodizing. A similar band was also found in the anodic films on ZE41 magnesium alloy [18]. Assuming that the light band is immobile during anodic film growth, the location of the band suggests that the film has grown by inward migration of anion species, forming the inner film region below the band, and the outward migration of cation species, forming the outer film region above the band. In this case, the transport number of cations $\left(t^{+}\right)$ is $\sim 0.6$, which is larger than those of amorphous anodic alumina $\left(t^{+}=0.4\right)$ [19] and anodic niobia and tantala $\left(t^{+}=0.24\right)[20,21]$. This is of interest, since crystalline anodic films, such as $\mathrm{ZrO}_{2}$ and $\mathrm{HfO}_{2}$, are formed predominantly by anion transport [21]. It is possible that ionic transport mechanism differs in the fluoride-based films from that in the oxide-based films. It is also possible that an amorphous phase is also present in addition to the crystalline $\mathrm{MgF}_{2}$ phase.

Quantitative compositional analysis was carried out by RBS. Figure 4 shows the experimental and simulated RBS spectra of the specimen anodized to $200 \mathrm{~V}$. The experimental spectrum is fitted well with the simulated one, obtained for a film composition of $\mathrm{MgF}_{1.8} \mathrm{O}_{0.1}$, with a density of $2.64 \mathrm{~g} \mathrm{~cm}^{-3}$ and thickness of $247 \mathrm{~nm}$. The composition of the anodic film is uniform in depth and the density of the anodic film is slightly lower than that of crystalline $\mathrm{MgF}_{2}\left(3.15 \mathrm{~g} \mathrm{~cm}^{-3}\right)$. It is found from the number of $\mathrm{Mg}^{2+}$ ions in the anodic films that the electric charge passed during anodizing to $200 \mathrm{~V}\left(0.20 \mathrm{C} \mathrm{cm}^{-2}\right)$ is the same as that used to form the anodic film. Thus, the current efficiency is almost $100 \%$. The Pilling-Bedworth ratio (PBR) during anodic film formation was also estimated. The value, which is the ratio of the volume of film materials formed with respect to the volume of magnesium metal, is 1.67 , being greater than unity. The difficulty of formation of protective surface films on magnesium and its alloys is often discussed in terms of the low PBR of 
$\mathrm{Mg} / \mathrm{MgO}(0.81)$ [22, 23]. Under this condition, the metal surface could not be covered entirely by the anodic film. The film formation under a PBR greater than unity and the development of $\mathrm{MgF}_{2}$-based films, which have been reported to improve the corrosion resistance of magnesium alloys [24], may be responsible for the growth of the present anodic films on magnesium at high current efficiency.

The present study demonstrates the uniform and highly efficient formation of anodic films on magnesium. This allows us to conduct fundamental studies on the ionic transport process in growing anodic films on magnesium. Such studies using tracers incorporated from electrolyte and substrate will be reported separately.

\section{Conclusions}

(1) Barrier-type anodic films are formed on magnetron-sputtered magnesium at high current efficiency in ethylene glycol electrolyte containing $\mathrm{NH}_{4} \mathrm{~F}$ and $\mathrm{H}_{2} \mathrm{O}$.

(2) The anodic films contain a crystalline $\mathrm{MgF}_{2}$ phase and the composition determined by RBS is $\mathrm{MgF}_{1.8} \mathrm{O}_{0.1}$ throughout the film thickness.

(3) Unlike $\mathrm{Mg} / \mathrm{MgO}$, the Pilling-Bedworth ratio for the formation of anodic films is 1.67, being greater than unity.

\section{Acknowledgments}

A part of this work was supported by the Light Metal Educational Foundation, Inc. and conducted at Hokkaido University, supported by the "Nanotechnology Platform" Program of the Ministry of Education, Culture, Sports, Science and Technology (MEXT), Japan.

\section{References}

[1] J.E. Gray, B. Luan, J. Alloys Compd., 336 (2002) 88-113.

[2] C. Blawert, W. Dietzel, E. Ghali, G.L. Song, Adv. Eng. Mater., 8 (2006) 511-533.

[3] J.M. Macak, P. Schmuki, Electrochim. Acta, 52 (2006) 1258-1264.

[4] M. Paulose, K. Shankar, S. Yoriya, H.E. Prakasam, O.K. Varghese, G.K. Mor, T.A. Latempa, A. Fitzgerald, C.A. Grimes, J. Phys. Chem. B, 110 (2006) 16179-16184.

[5] S. Berger, J. Faltenbacher, S. Bauer, P. Schmuki, Physica Status Solidi-Rapid Research Letters, 2 (2008) 102-104.

[6] S. Berger, F. Jakubka, P. Schmuki, Electrochem. Commun., 10 (2008) 1916-1919.

[7] J.Z. Ou, R.A. Rani, M.H. Ham, M.R. Field, Y. Zhang, H. Zheng, P. Reece, S. Zhuiykov, S. Sriram, M. Bhaskaran, R.B. Kanee, K. Kalantar-Zadeh, ACS Nano, 6 (2012) 4045-4053.

[8] W. Wei, J.M. Macak, P. Schmuki, Electrochem. Commun., 10 (2008) 428-432.

[9] H.E. Prakasam, O.K. Varghese, M. Paulose, G.K. Mor, C.A. Grimes, Nanotechnol., 17 (2006) 4285-4291.

[10] R.R. Rangaraju, A. Panday, K.S. Raja, M. Misra, J. Phys. D: Appl. Phys., 42 (2009) 135303.

[11] H. Habazaki, Y. Konno, Y. Aoki, P. Skeldon, G.E. Thompson, J. Phys. Chem. C, 114 (2010) 18853-18859. 
[12] K. Kure, Y. Konno, E. Tsuji, P. Skeldon, G.E. Thompson, H. Habazaki, Electrochem. Commun., 21 (2012) $1-4$.

[13] J.G. Brunner, R. Hahn, J. Kunze, S. Virtanen, J. Electrochem. Soc., 156 (2009) C62-C66.

[14] H. Asoh, S. Ono, Anodizing of magnesium in amine - ethylene glycol electrolyte, in: Y. Kojima, T. Aizawa, K. Higashi, S. Kamado (Eds.) Magnesium Alloys 2003, Pts 1 and 2, vol. 419-4, Trans Tech Publications Ltd, Zurich-Uetikon, 2003, pp. 957-961.

[15] M.C. Turhan, R.P. Lynch, H. Jha, P. Schmuki, S. Virtanen, Electrochem. Commun., 12 (2010) 796-799.

[16] A. Climent-Font, V. Watjen, H. Bax, Nucle. Instr. and Meth., B71 (1992) 81-86.

[17] A.C. Harkness, L. Young, Can. J. Chem., 44 (1966) 2409-2413.

[18] J.M. Hernández-López, A. Nemcova, X.L. Zhong, H. Liu, M.A. Arenas, S.J. Haigh, M.G. Burke, P. Skeldon, G.E. Thompson, Electrochim. Acta, Submitted.

[19] F. Brown, W.D. Mackintosh, J. Electrochem. Soc., 120 (1973) 1096-1102.

[20] J.P.S. Pringle, J. Electrochem. Soc., 120 (1973) 398-407.

[21] J.P.S. Pringle, Electrochim. Acta, 25 (1980) 1423-1437.

[22] K.M. Ismail, S. Virtanen, Electrochemical and Solid-State Letters, 10 (2007) C9.

[23] M. Taheri, J.R. Kish, J. Electrochem. Soc., 160 (2013) C36-C41.

[24] F. Witte, J. Fischer, J. Nellesen, C. Vogt, J. Vogt, T. Donath, F. Beckmann, Acta Biomaterialia, 6 (2010) 1792-1799. 
Figure captions

Fig. 1. Scanning electron micrographs of the surfaces of the magnesium specimens (a) as-deposited, (b) anodized to $200 \mathrm{~V}$ in ethylene glycol electrolyte containing $0.1 \mathrm{~mol} \mathrm{dm}{ }^{-3}$ $\mathrm{NH}_{4} \mathrm{~F}$ and $0.1 \mathrm{~mol} \mathrm{dm}^{-3} \mathrm{H}_{2} \mathrm{O}$ and (c) anodized to $50 \mathrm{~V}$ in aqueous electrolyte containing 0.1 $\mathrm{mol} \mathrm{dm}{ }^{-3} \mathrm{NH}_{4} \mathrm{~F}$.

Fig. 2. XRD pattern of the magnetron-sputtered magnesium specimen anodized to $350 \mathrm{~V}$ in ethylene glycol electrolyte containing $0.1 \mathrm{~mol} \mathrm{dm}^{-3} \mathrm{NH}_{4} \mathrm{~F}$ and $0.1 \mathrm{~mol} \mathrm{dm}^{-3} \mathrm{H}_{2} \mathrm{O}$ at $293 \mathrm{~K}$.

Fig. 3. (a) Transmission electron micrograph and (b) selected area electron diffraction pattern of the anodic film formed on the magnetron-sputtered magnesium specimen anodized to $350 \mathrm{~V}$ in ethylene glycol electrolyte containing $0.1 \mathrm{~mol} \mathrm{dm}^{-3} \mathrm{NH}_{4} \mathrm{~F}$ and $0.1 \mathrm{~mol} \mathrm{dm}^{-3} \mathrm{H}_{2} \mathrm{O}$ at $293 \mathrm{~K}$.

Fig. 4. Experimental and simulated Rutherford backscattering spectra of the magnetron-sputtered magnesium specimen anodized to $350 \mathrm{~V}$ in ethylene glycol electrolyte containing $0.1 \mathrm{~mol} \mathrm{dm}^{-3} \mathrm{NH}_{4} \mathrm{~F}$ and $0.1 \mathrm{~mol} \mathrm{dm}^{-3} \mathrm{H}_{2} \mathrm{O}$ at $293 \mathrm{~K}$. 

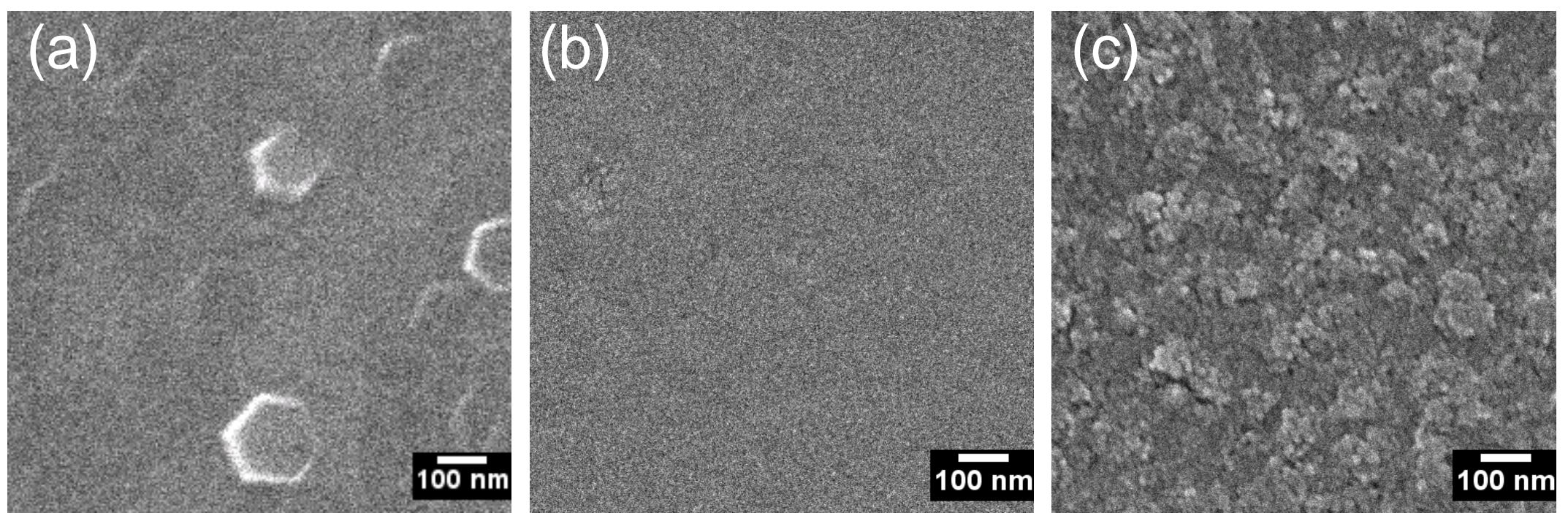

Fig. 1 Scanning electron micrographs of surfaces of the magnesium specimens (a) as-deposited, (b) anodized to $200 \mathrm{~V}$ in ethylene glycol electrolyte containing $0.1 \mathrm{~mol} \mathrm{dm}^{-3} \mathrm{NH}_{4} \mathrm{~F}$ and $0.1 \mathrm{~mol} \mathrm{dm}^{-3} \mathrm{H}_{2} \mathrm{O}$ and (c) anodized to $50 \mathrm{~V}$ in aqueous electrolyte containing $0.1 \mathrm{~mol} \mathrm{dm}^{-3} \mathrm{NH}_{4} \mathrm{~F}$. 


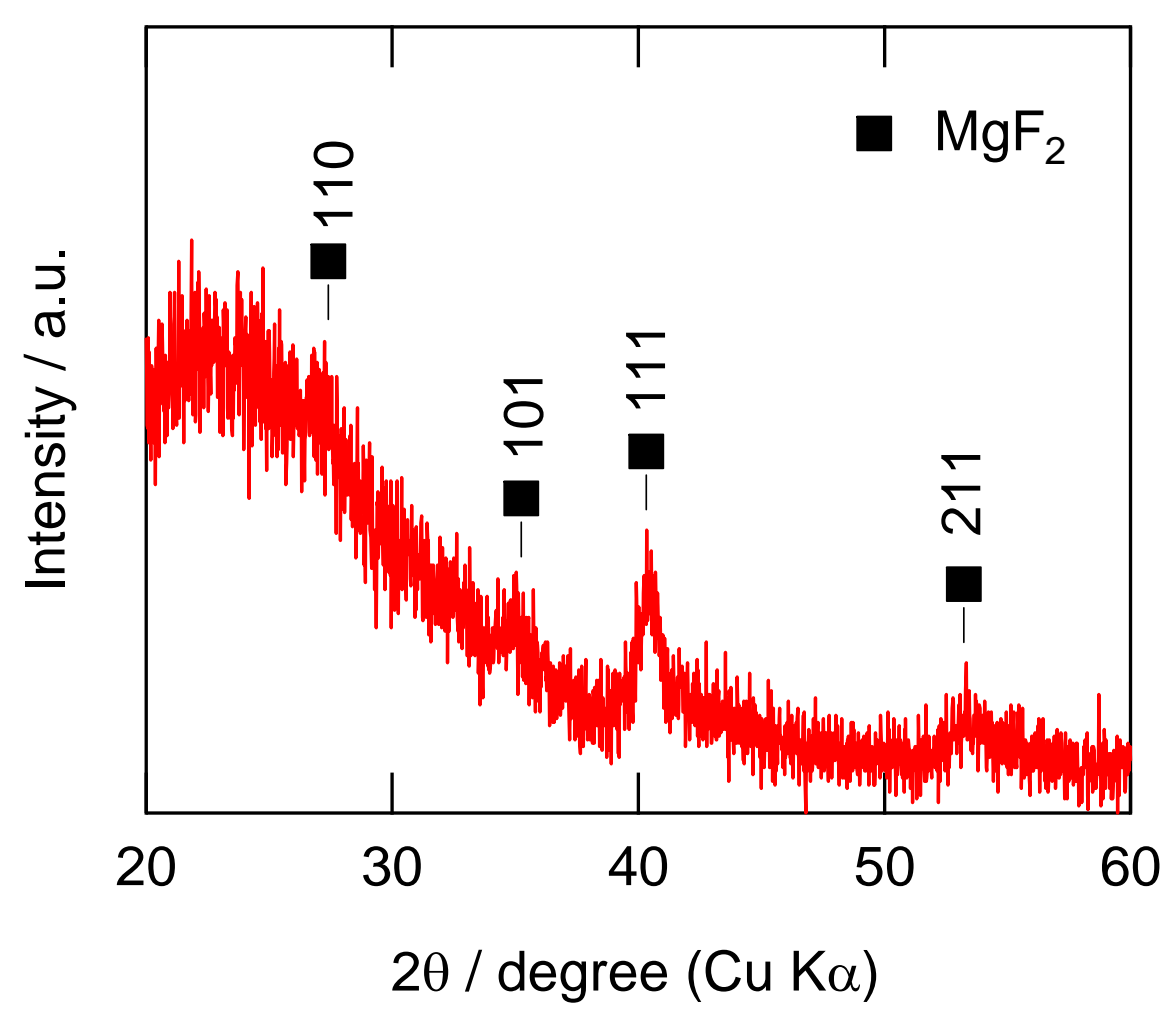

Fig. 2 XRD pattern of the magnetron-sputtered magnesium specimen anodized to $350 \mathrm{~V}$ in ethylene glycol electrolyte containing $0.1 \mathrm{~mol} \mathrm{dm}^{-3} \mathrm{NH}_{4} \mathrm{~F}$ and $0.1 \mathrm{~mol} \mathrm{dm}^{-3}$ $\mathrm{H}_{2} \mathrm{O}$ at $293 \mathrm{~K}$. 


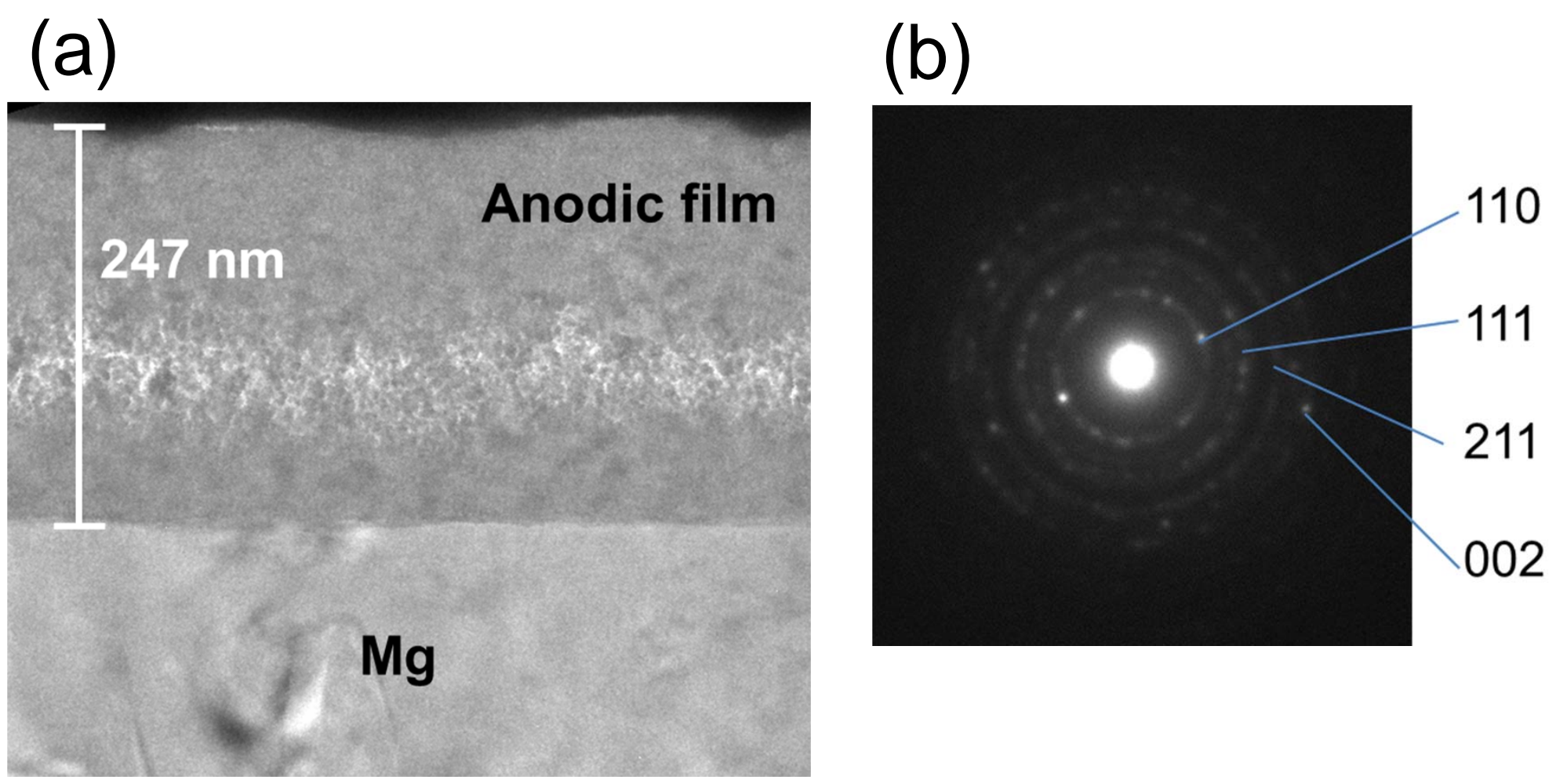

Fig. 3 (a) Transmission electron micrograph and (b) selected area electron diffraction pattern of the anodic film formed on the magnetron-sputtered magnesium specimen anodized to $350 \mathrm{~V}$ in ethylene glycol electrolyte containing $0.1 \mathrm{~mol} \mathrm{dm}^{-3} \mathrm{NH}_{4} \mathrm{~F}$ and 0.1 mol dm ${ }^{-3} \mathrm{H}_{2} \mathrm{O}$ at $293 \mathrm{~K}$. 


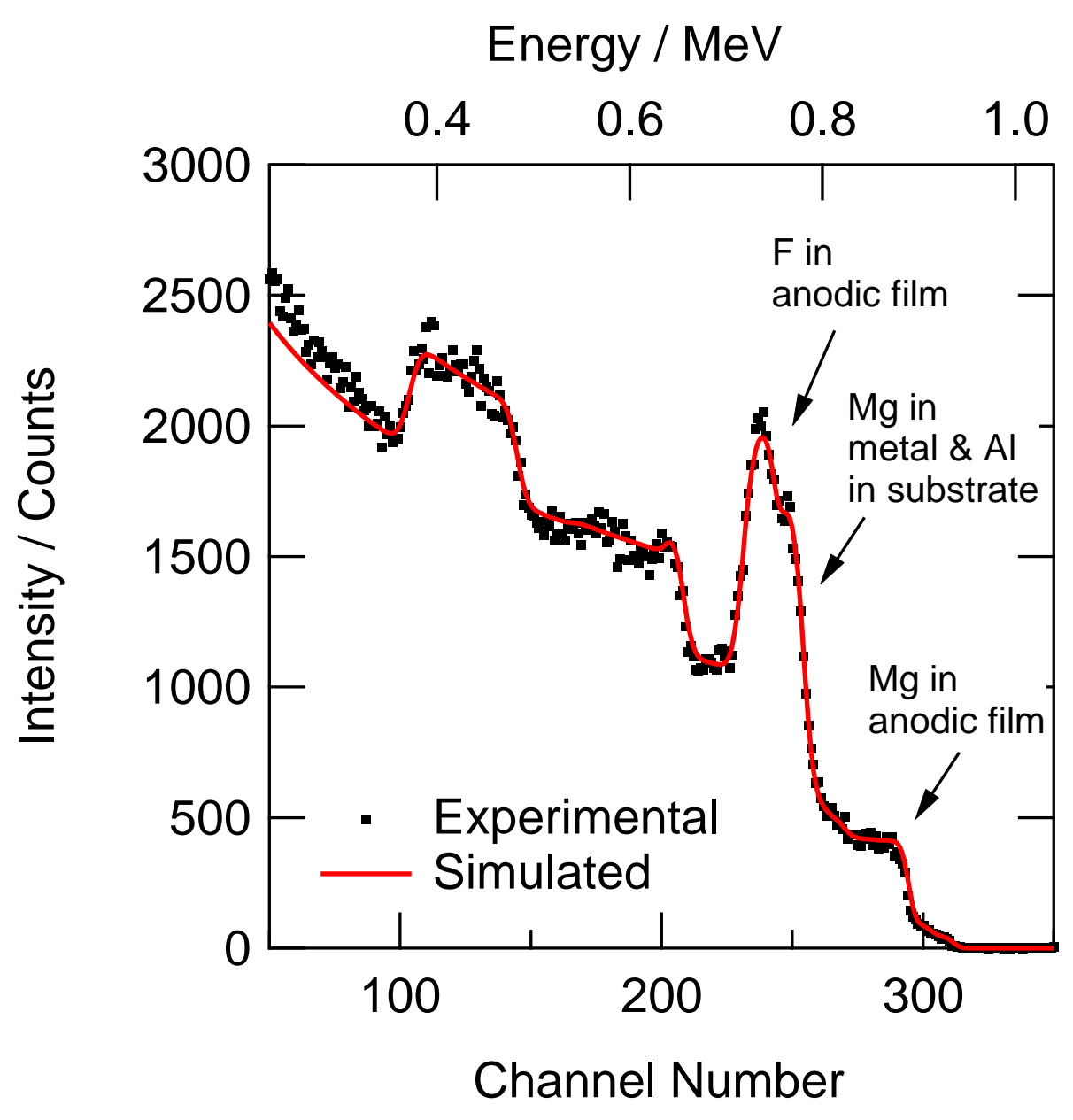

Fig. 4 Experimental and simulated Rutherford backscattering spectra of the magnetronsputtered magnesium specimen anodized to $350 \mathrm{~V}$ in ethylene glycol electrolyte containing $0.1 \mathrm{~mol} \mathrm{dm}^{-3} \mathrm{NH}_{4} \mathrm{~F}$ and $0.1 \mathrm{~mol} \mathrm{dm}^{-3} \mathrm{H}_{2} \mathrm{O}$ at $293 \mathrm{~K}$. 